\title{
Agenda Redes
}

\section{Unión Latinoamericana}

de Extensión Universitaria (ULEU)

- Avance sobre el fortalecimiento institucional de la ULEU.

- Organización del XII Congreso Iberoamericano de Extensión: Integración extensión, docencia, investigación para la transformación y el bienestar social. Del 19 al 22 de noviembre de 2013. Universidad Central de Quito. Ecuador.

\section{Asociación Universidades del Grupo Montevideo (AUGM) Comisión Permanente} de Extensión Universitaria

- Organización del II Plenario de la Comisión Permanente de Extensión Universitaria que se realizará en la Universidad de Playa Ancha (Valparaíso, Chile), en el segundo semestre de 2013.

- Realización de las I Jornadas de Extensión de AUGM en la Universidad de la República (Uruguay) en el primer semestre de 2013. Se garantizará la gratuidad para la participación de los estudiantes universitarios.

\section{Consejo Interuniversitario} Nacional. Red Nacional de Extensión Universitaria (REXUNI)

- Plan Estratégico de Extensión 2012- 2015 (Acuerdo Plenario CIN 811/12): definición de metas, variables e indicadores.

- Internacionalización de la Extensión (Acuerdo Plenario CIN 812/12): Propuesta de trabajo.

- Intensificación de la capacitación para evaluadores de programas y proyectos de extensión designados por las universidades.

- Actualización del Banco de Evaluadores para todas las universidades que lo requieran. 